\title{
Removal of Dyes from Aqueous Solution by Adsorption onto CTAB Modified Attapulgite
}

\author{
Minhong Xu \\ Department of Materials Chemistry \\ Huzhou University \\ Huzhou, China \\ e-mail:xumh123@163.com \\ Jing Li \\ Department of Materials Chemistry \\ Huzhou University \\ Huzhou, China \\ e-mail: 1772256889@qq.com
}

\author{
Jvxiang Wang \\ Department of Materials Chemistry \\ Huzhou University \\ Huzhou, China \\ e-mail: 1004309354@qq.com \\ Yunfeng $\mathrm{Wu}$ \\ Department of Materials Chemistry \\ Huzhou University \\ Huzhou, China \\ e-mail: 1772256889@qq.com
}

\begin{abstract}
In order to improve the adsorption performance of Attapulgite (ATP) on dyes. ATP was modified by cetyl trimethyl ammonium bromide (CTAB), and the ATP before and after modified were characterized with XRD and FT-IR. The results showed that ATP had been modified with CTAB successfully, and crystal structure of ATP was unchanged. The influence factors such as modified agent dosage, solution temperature, pH value of solution and dyes structure on adsorption properties of ATP were discussed. The results suggested that the optimal dosage of modifier was $10 \mathrm{wt} \%$ based on the quality of ATP. ATP had good adsorption effect on methyl orange when the $\mathrm{pH}$ value was $\mathrm{pH}$ value was in the rage of 3.6 to 11.6, temperature was in the range of 30 $50{ }^{\circ} \mathrm{C}$. The order of adsorption effect was as follow: methyl orange $>$ methylene blue $>$ amido black $>$ methyl blue $>$ congo red>rhodamine $B$.
\end{abstract}

Keywords-attapulgite; cetyl trimethyl ammonium bromide; adsorption; modification; dyes

\section{INTRODUCTION}

Recently, dye is extensively used in many industries, such as textiles, paper, printing and leather [1]. But the wastewaters containing dye are difficult to remove by conventional wastewater treatment methods because of the stability of the dyes under oxidants or light irradiation [2]. However, adsorption technique is widely used to treat the dye wastewater due to simple operation, low cost and circulating reuse of absorbents in practical application [3, 4]. Attapulgite (ATP), a species of hydrated magnesium aluminum silicate mineral $\left[\left(\mathrm{H}_{2} \mathrm{O}\right)_{4}(\mathrm{Mg}, \mathrm{Al}, \mathrm{Fe})_{5}(\mathrm{OH})_{2-}\right.$ $\mathrm{Si}_{8} \mathrm{O}_{20} \cdot 4 \mathrm{H}_{2} \mathrm{O}$ ] with commonly a rod-like morphology, possesses high surface area and moderate cation exchange capacity [5], which is beneficial for the adsorption of many pollutants such as heavy metals [6], dyes [7, 8] and phenol [9] from wastewater.

In this experiment, attapulgite (ATP) was modified with cetyl trimethyl ammonium bromide (CTAB), and the ATP before and after modified were characterized by XRD and FT-IR. The adsorption properties of modified ATP for adsorption of methyl orange (MO) was examined through comparative experiments. The effects of the amount of modifier, solution temperature, and $\mathrm{pH}$ value of solution on adsorption experiments were studied. Under the same experimental conditions, the adsorption of different dyes such as rhodamine B, methyl blue, amido black, methylene blue and congo red were carried out.

\section{EXPERIMENTAL}

\section{A. Materials}

CTAB, methyl orange (MO), rhodamine $\mathrm{B}$, methyl blue, amido black, methylene blue and congo red were purchased from Aladdin Industrial Corporation (Shanghai, China). The pristine ATP clay powder was supplied by Jiangsu Junda Attapulgite Material Co., Ltd. with mesh number is 50 .

\section{B. The Modification of ATP}

ATP was organically modified according to the following procedure. $5 \mathrm{~g}$ ATP, a certain quality of CTAB and $200 \mathrm{~mL}$ distilled water were slowly poured into 250 $\mathrm{mL}$ conical flask, than stirring at $80{ }^{\circ} \mathrm{C}$ for $3 \mathrm{~h}$. The ATP power was washed with distilled water and ethyl alcohol until there was no bubble in filtrate. After that, the power was dried at $50{ }^{\circ} \mathrm{C}$ for $5 \mathrm{~h}$ to get modified ATP (CTABATP).

\section{Adsorption Experiments}

The CTAB-ATP $(0.2 \mathrm{~g})$ mentioned above were immersed in MO solution $(100 \mathrm{mg} / \mathrm{L}, 100 \mathrm{~mL})$, while stirring at a certain temperature. A certain volume of supernatant liquor was taken out and analyzed on a 722 spectrophotometer using distilled water as reference at $\lambda \max$ of $465 \mathrm{~nm}$. The adsorption efficiency was calculated using the following equation:

Remaining rate $=\mathrm{C}_{\mathrm{t}} / \mathrm{C}_{0}$

where $\mathrm{C}_{0}$ is the initial concentration of $\mathrm{MO}$ solution, $\mathrm{C}_{t}$ is the concentration of $\mathrm{MO}$ solution after a certain reaction time. 


\section{RESULTS AND DISCUSSION}

\section{A. XRD Analysis of Attapulgite}

The X-ray diffraction (XRD) pattern of modified ATP was shown in Fig. 1, which was recorded on XD-6 diffractometer with $\mathrm{Cu}$ target $(36 \mathrm{kV}, 20 \mathrm{~mA})$ at a scanning rate of $2 \% \mathrm{~min}$. The typical diffraction peaks at $2 \theta=8.3^{\circ}, 19.7^{\circ}$ and $27.3^{\circ}$ in Fig. 1(a) shown good agreement with primary diffraction of the (110), (040) and (400) planes of the attapulgite [10]. After modified with CTAB, no obvious other peaks could be observed in Fig. 1 (b) compared with ATP, which proved CTAB did not change the original crystal structure of attapulgite.

\section{B. IR Analysis of Modified Attapulgite}

The structure of CTAB-ATP was characterized with a Nicolet 5700 FT-IR instrument. FT-IR spectra of ATP power and those modified with CTAB were presented in Fig. 2.

There was broad band at around $3582 \mathrm{~cm}^{-1}$ and 3434 $\mathrm{cm}^{-1}$ in FT-IR spectra curve a (ATP) were attributed to the stretching vibrations of -OH groups. The absorption peaks at $1684 \mathrm{~cm}^{-1}$ was ascribed to the bending vibrations of -OH groups. In addition, the absorption peaks at $1043 \mathrm{~cm}^{-1}$ was ascribed to the stretching vibrations of -Si-O-Si groups [11]. The absorption peaks at 2913 and $2835 \mathrm{~cm}^{-1}$ just as curve b (CTAB) shown were attributed to the asymmetrical stretching vibration and symmetric stretching vibrations of $\mathrm{C}-\mathrm{O}$ groups. However, there was obvious asymmetrical stretching vibration and symmetric stretching vibrations of $\mathrm{C}-\mathrm{O}$ groups in curve c (CTABATP), compared with curve a. These results indicated that ATP had been modified with CTAB successfully.

\section{Effect of Modifier Dosage}

The dosage of CTAB is one of important elements which can influence the adsorption effect. So the effect of CTAB dosage on adsorption of $\mathrm{MO}$ was investigated. The CTAB were $10 \mathrm{wt} \%, 20 \mathrm{wt} \%, 30 \mathrm{wt} \%$ and $40 \mathrm{wt} \%$ respectively, based on the quality of ATP, the results shown in Fig. 3.

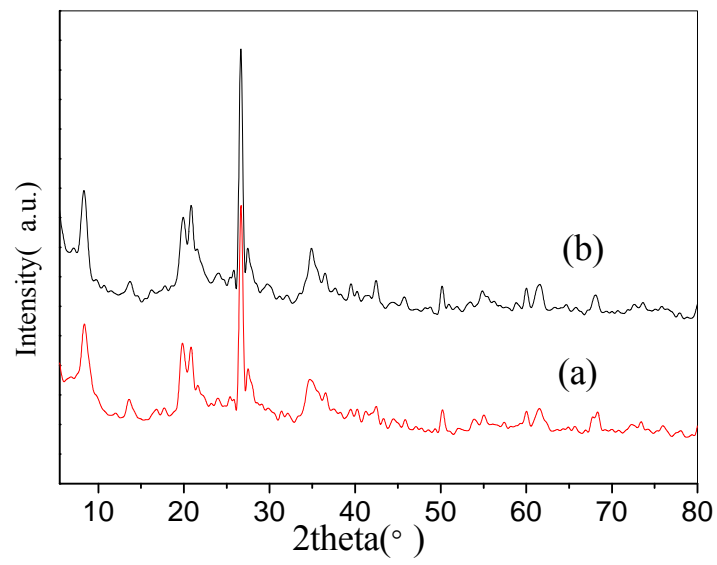

Figure 1. X-ray diffraction patterns of ATP (a) and CTAB-ATP(b)

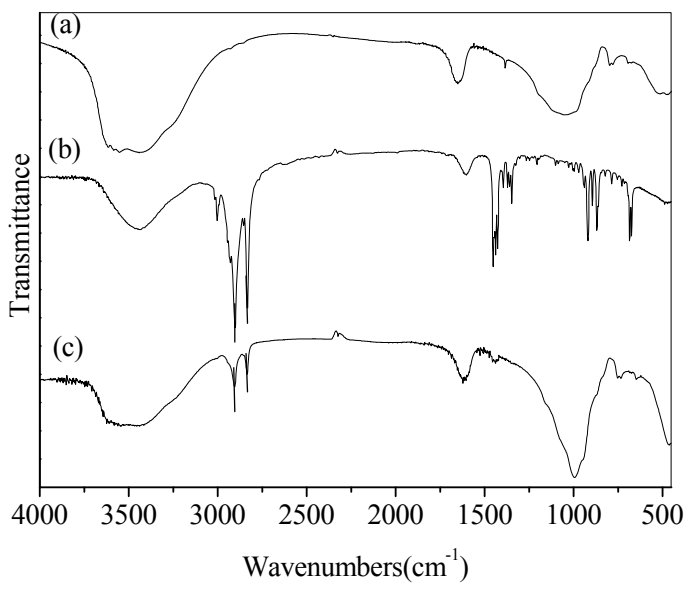

Figure 2. FT-IR spectrum of ATP (a), CTAB (b) and CTAB-ATP (c)

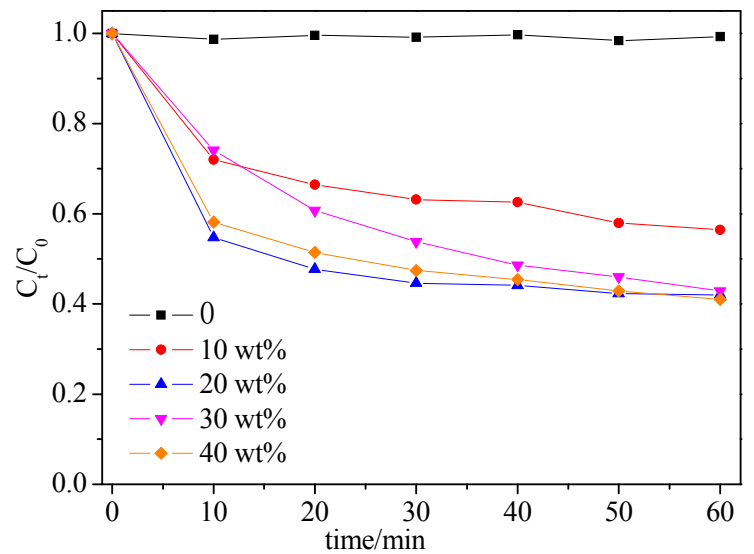

Figure 3. Effect of modifier dosage on Adsorption (CTAB-ATP $0.2 \mathrm{~g}$, MO $100 \mathrm{mg} / \mathrm{L}, 100 \mathrm{~mL}, \mathrm{~T} 30^{\circ} \mathrm{C}, \mathrm{pH} 7.6$ )

The remaining rate of $\mathrm{MO}$ in solution almost unchanged after adsorption for $60 \mathrm{~min}$, indicating unmodified ATP almost had no adsorption of methyl orange. When the modifier dosage was $10 \mathrm{wt} \%$, the remaining rate of $\mathrm{MO}$ in aqueous solution was $56.2 \%$ after adsorption for $60 \mathrm{~min}$. When the modifier dosage was 20 $\mathrm{wt} \%$, the remaining rate of $\mathrm{MO}$ was $42.3 \%$. When the modifier dosage reached to $40 \mathrm{wt} \%$, the remaining rate was the minimum $41.0 \%$. This may be due to the surface area and cation exchange capacity of ATP were limited, too high modifier density in the solution would impact the adsorption and reaction between modifier and ATP surface. So the adsorption was slightly affected by the modifier dosage, the optimal dosage of modifier was $10 \mathrm{wt} \%$.

\section{Effect of $p H$}

The effect of solution $\mathrm{pH}$ value on adsorption of $\mathrm{MO}$ was studied by varying the initial $\mathrm{pH}$ value in $100 \mathrm{~mL}$ of MO solution $(100 \mathrm{mg} / \mathrm{L})$ on $0.2 \mathrm{~g}$ of CTAB-ATP at $30{ }^{\circ} \mathrm{C}$. The results of $\mathrm{MO}$ remaining rate versus $\mathrm{pH}$ value were shown in Fig. 4. When the $\mathrm{pH}$ value was 3.6, the remaining rate of $\mathrm{MO}$ in aqueous solution was $7.6 \%$ after adsorption for $60 \mathrm{~min}$. When the $\mathrm{pH}$ value was 5.6, 7.6, 9.6, and 11.6 , respectively, the remaining rate were $22.3 \%$, $25.4 \%, 23.3 \%$ and $24.8 \%$, respectively. It was found that when the $\mathrm{pH}$ value of the solution was acidic, adsorptive 
effect of CTAB-ATP remarkably increased, the adsorption rate reached more than $90 \%$. In addition, there was no difference of remaining rates in alkaline solution and neutral solution. Therefore CTAB-ATP has good adsorption effect on $\mathrm{MO}$ when the $\mathrm{pH}$ value was in the rage of 3.6 to 11.6 .

\section{E. Effect of Temperature}

The effect of different temperatures on CTAB-ATP adsorption of MO was shown in Fig. 5. At 30, 35, 40, 45 and $50{ }^{\circ} \mathrm{C}$, the remaining rates of MO were $25.4 \%, 27.9 \%$, $25.8 \%, 22.9 \%$ and $24.3 \%$, respectively, after adsorption for $60 \mathrm{~min}$. The results indicated that the adsorption of $\mathrm{MO}$ on CTAB-ATP was slightly affected by the temperature, and the adsorption can be carried out at temperature $\left(30{ }^{\circ} \mathrm{C}\right.$ to $50{ }^{\circ} \mathrm{C}$ ) in practical application.

\section{F. Effect of Dye Structure}

In order to study the effect of dye structure on adsorption properties of CTAB-ATP, the experiments that adsorption of rhodamine $\mathrm{B}$, congo red, methyl blue, amido black, methylene blue and methyl orange on CTAB-ATP were carried out under the conditions of CTAB-ATP $0.2 \mathrm{~g}$, modifier dosage $10 \mathrm{wt} \%$, dye $100 \mathrm{mg} / \mathrm{L}, 100 \mathrm{~mL}, \mathrm{pH} 7.6$, the results shown in Fig. 6. The remaining rates of rhodamine $\mathrm{B}$, congo red, methyl blue, amido black, methylene blue and methyl orange were $32.9 \%, 25.4 \%$, $19.0 \%, 10.1 \%, 9.9 \%$ and $2.3 \%$, respectively, after adsorption for $60 \mathrm{~min}$, the structures of dyes as seen in Fig. 7.

The adsorption effect of methyl orange was best, compared to other dyes. The order of their adsorption effect was as follow: methyl orange $>$ methylene blue $>$ amido black $>$ methyl blue $>$ congo red $>$ rhodamine $B$. The structures of azo days as congo red and rhodamine B were relatively stable, so it was difficult to be adsorbed. The remaining rates of methyl orange, methylene blue, amido black and methyl blue was relatively low. That indicated when the amount of sulfonic acid groups in the same type of dyes was more, it is conducive to adsorption. When the number of sulfonic acid groups is the same, the larger the molecular structure of dyes was, the worse adsorption effect was.

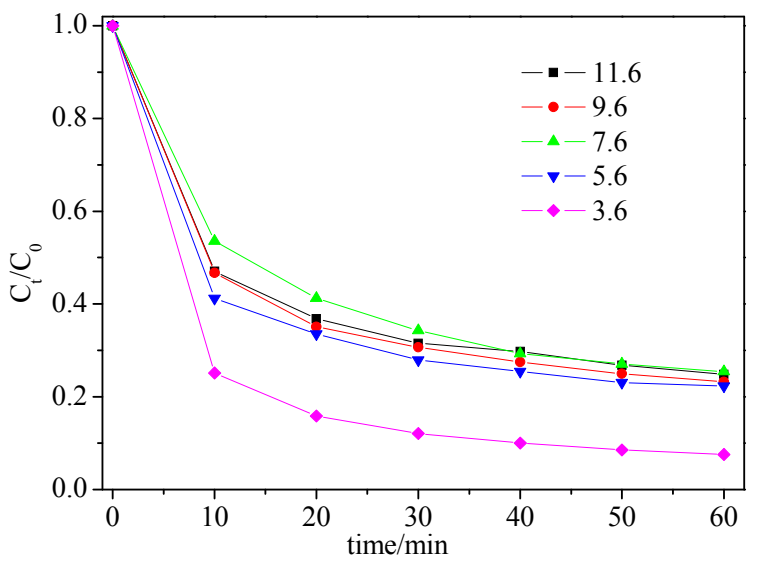

Figure 4. Effect of $\mathrm{pH}$ value on adsorption (CTAB-ATP $0.2 \mathrm{~g}$, modifier dosage $10 \mathrm{wt} \%$, MO $100 \mathrm{mg} / \mathrm{L}, 100 \mathrm{~mL}, \mathrm{~T} 30^{\circ} \mathrm{C}$ )

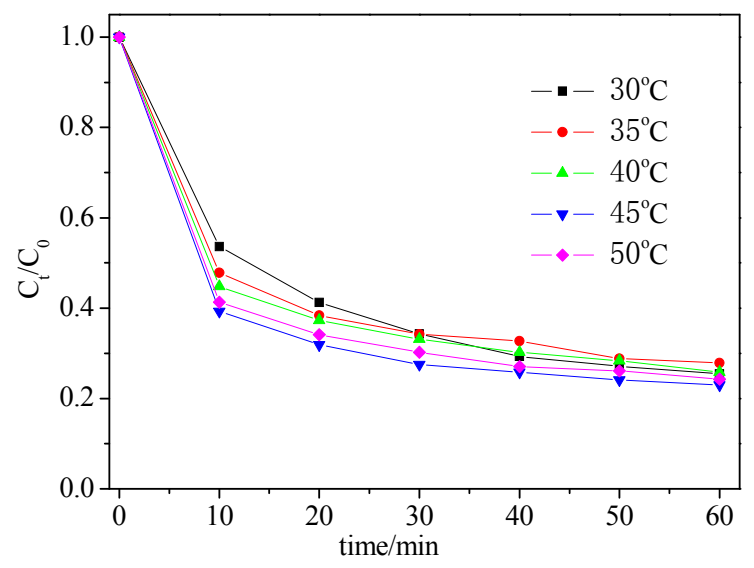

Figure 5. Effect of temperature on adsorption (CTAB-ATP $0.2 \mathrm{~g}$, modifier dosage $10 \mathrm{wt} \%$, MO $100 \mathrm{mg} / \mathrm{L}, 100 \mathrm{~mL}, \mathrm{pH} 7.6$ )

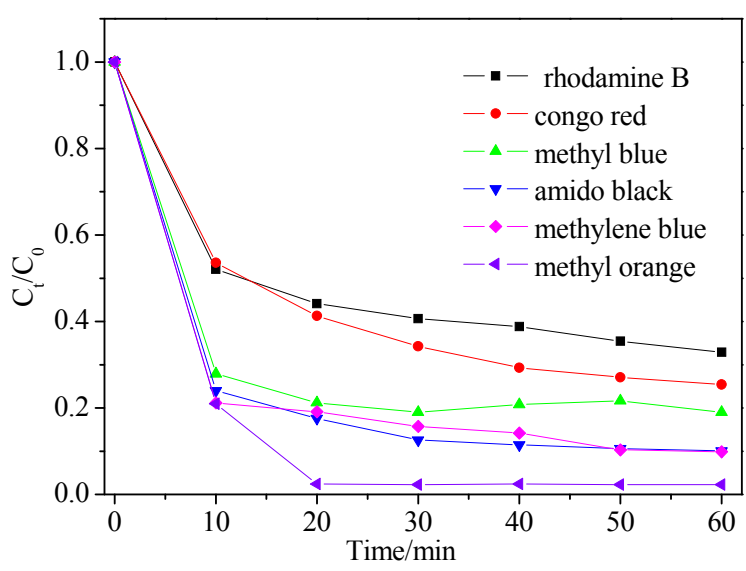

Figure 6. Effect of dye structure on adsorption (CTAB-ATP $0.2 \mathrm{~g}$, modifier dosage $10 \mathrm{wt} \%$, dyes $100 \mathrm{mg} / \mathrm{L}, 100 \mathrm{~mL}, \mathrm{pH} 7.6$ )
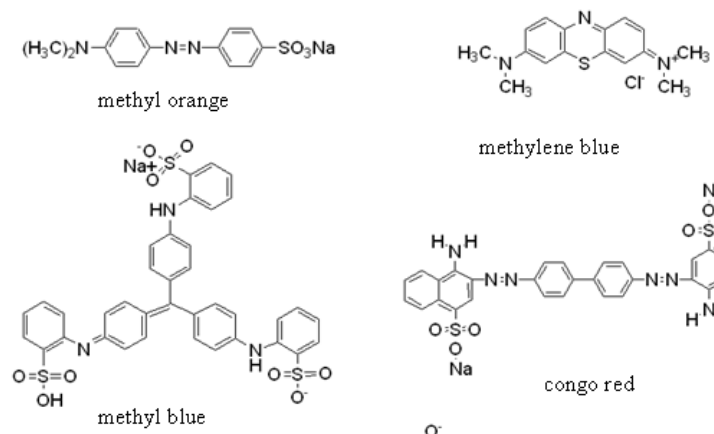

methylene blue
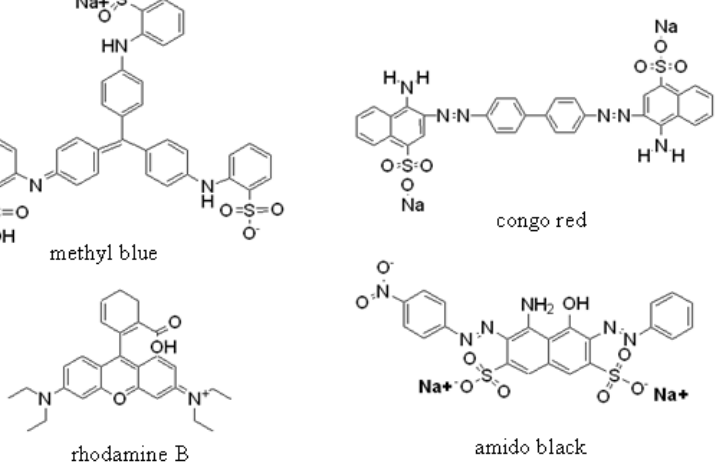

Figure 7. The structures of dyes

\section{CONCLUSIONS}

Attapulgite (ATP) was modified with cetyl trimethyl ammonium bromide (CTAB), and the ATP before and after modified were characterized with XRD and FT-IR. The results of characterization showed that ATP had been modified with CTAB successfully, and crystal structure of ATP was unchanged. The influence factors such as 
modified agent dosage, solution temperature, $\mathrm{pH}$ value of solution and day structure on adsorption properties of ATP were discussed. The results showed that the optimal dosage of modifier was $10 \mathrm{wt} \%$ based on the quality of ATP. ATP had good adsorption effect on methyl orange when the $\mathrm{pH}$ value was in the rage of 3.6 to 11.6 , temperature was from 30 to $50{ }^{\circ} \mathrm{C}$. The order of adsorption effect of modified ATP was as follow: methyl orange $>$ methylene blue $>$ amido black $>$ methyl blue $>$ congo red $>$ rhodamine $\mathrm{B}$.

\section{ACKNOWLEDGMENT}

Authors wish to thank for the financial support of scientic research project of Huzhou University (2015XJKY30).

\section{REFERENCES}

[1] T. Madrakian, A. Afkhami, H. Mahmood-Kashani and M. Ahmadi, "Adsorption of some cationic and anionic dyes on magnetite nanoparticles-modified activated carbon from aqueous solutions: equilibrium and kinetics study, "Journal of the Iranian Chemical Society, vol. 10, Jun. 2013, pp. 481-489, doi: 10.1007/s13738-0120182-4.

[2] W. S. Wan Ngaha, L. C. Teonga and M. A. K .M Hanafiah, "Adsorption of dyes and heavy metal ions by chitosan composites: A reviews," Carbohydrate Polymers, vol. 83, Feb. 2011, pp. 1446 1456, doi: 10.1016/j.carbpol.2010.11.004.

[3] D. Wang, P. Lv, Y. Yan, H. Liu and G. Wang, "Adsorption of methylene blue from aqueous solution on attapulgite, " Chinese Journal of Reactive Polymers, vol. 16, Jan. 2007, pp. 85- 89, doi: 1004-7646(2007)02-0085-05.
[4] B. Liu, D. Wang, G. Yu and X. Meng, "Adsorption of heavy metal ions, dyes and proteins by chitosan composites and derivatives A review," Journal of Ocean University of China, vol. 12, Mar. 2013, pp. 500-508, 2013 doi: 10.1007/s11802-013-2113-0.

[5] Y. Fang and D. Chen, "A novel catalyst of Fe-octacarboxylic acid phthalocyanine supported by attapulgite for degradation of Rhodamine B," Materials Research Bulletin, vol. 45, Jul. 2010, pp. 1728-1731, doi:10.1016/j.materresbull.2010.06.062.

[6] H. Chen, Y. Zhao and A. Wang, "Remove of $\mathrm{Cu}(\mathrm{II})$ from aqueous solution by adsorption onto acid-activated palygroskite," Journal of Hazardous Materials, vol. 149, 2007, pp.346-345, doi: 10.1016/j.jhazmat.2007.03.085.

[7] H. Chen and J. Zhao, "Adsorption study for removal of Congo red anionic dye using organo-attapulgite," Adsorption, vol. 15, Aug. 2009, pp. 381-389, doi: 10.1007/s10450-009-9155-z.

[8] J. H. Huang, Y. F. Liu, Q. Z. Jin, X. Wang and J. Yang, "Adsorption studies of a water soluble dye, Reactive Red MF-3B, using sonication-surfactant-modified attapulgite clay," Journal of Hazardous Materials, vol. 143, May. 2007, pp. 541-548, doi: 10.1016/j.jhazmat.2006.09.088.

[9] J. Huang, X. Wang, Q. Jin, Y. Liu and Y. Wang, "Removal of phenol from aqueous solution by adsorption onto OTMACmodified attapulgite,'Journal of Environmental Management, vol 84, Jul. 2007, pp. 229-36, doi:10.1016/j.jenvman.2006.05.007.

[10] W. Zhu, Z. Liu, L. Chen and Y. Dong, "Sorption of uranium(VI) on Na-attapulgite as a function of contact time, solid content, $\mathrm{pH}$, ionic strength, emperature and humic acid," Journal of Radioanalytical and Nuclear Chemistry, vol. 289, Sep. 2011, pp. 781-788, doi: 10.1007/s10967-011-1129-4.

[11] D. M. A. Melo, J. A. C. Ruiz, M. A. F. Melo, E.V Sobrinho, and M Schmall, "Preparation and characterization of terbium palygorskite clay as acid catalyst," Microporous and Mesoporous Materials, vol. 38, Aug. 2000, pp. 345-349, doi: 10.1016/S13871811(00)00155-4 